\title{
A Framework for Success: Australia Awards Scholars in the Philippines
}

\author{
Gilbert A. Importante, Eleonor T. Callena, \\ Gilbert M. Gordo and Jeanette A. Pedriña ${ }^{1}$
}

\begin{abstract}
The level of success achieved by returning Australia Awards scholars varies. Success is measured in relation to the implementation of Re-Entry Action Plans (REAP), degree of change introduced in the workplace, and personal development. However, the level of success of returning scholars has not been studied. In fact, some scholars were considered less successful, and there were cases wherein they were unable to implement or complete their REAPs. This study aimed to develop a framework to show contrasting factors that contribute to scholars' success levels. A sequential exploratory mixed method was utilized. The scholars' assignment (their workload/designation/rank in their employing organization) and qualities, their motivation, and the extent of scholarship support were considered facilitating factors in their level of success. However, colleagues and support from superiors were found to be hindering factors. Multiple regression reinforced that assignment appeared to be a predictor of success for returning scholars and to some
\end{abstract}

Drs. Importante, Callena and Pedriña are faculty of the College of Teacher Education and Technology. Dr. Gordo is a faculty of the College of Business Administration.

Contact the authors at g.importante@usep.edu.ph, e.callena@usep.edu.ph, j.pedrina@usep.edu.ph and g.gordo@usep.edu.ph 
extent scholars' qualities may also facilitate their success. Consequently, in selecting potential grantees for Australia Awards, work-related indicators and personal qualities may be useful factors to be considered in the scholars' selection criteria.

Keywords: Australia Awards, success framework, PAHRODF

The Philippines-Australia Human Resource and Organizational Development Facility (PAHRODF) of the Department of Foreign Affairs and Trade (DFAT) is the agency tasked to manage the Australia Awards Scholarships (AAS) in the Philippines. It has been in operation since 2004 and provides scholarship grants to government agencies and private organizations in human resource management and development, policy and planning, management and leadership, financial administration, and organizational capacities and systems to support service delivery (Coffey International Limited, 2015).

To date, more than a thousand scholars have been sent by the Australian government to various Australian organizations for scholarships in different fields. Most of these scholars currently handle strategic positions in their respective organizations, develop strategies to improve delivery systems and serve as managers, planners and in some cases entrepreneurs.

One of the AAS's strategies to ensure the contribution of AA scholarship awardees is to require them to implement a Re-entry Action Plan (REAP). The REAP is a feature of the program unique to the Philippines, which requires recipients to make use of the skills, knowledge and networks they gained from their studies in Australia. The 
REAP is aimed to develop and implement relevant programs and projects that contribute to Philippine development. Through their REAPs, AA scholars outline how their education and enhanced competencies from Australia contribute to the development of their organizations and communities when they return to the Philippines (Australia Awards Philippines, n.d.).

Although anecdotal evidence suggests that AA scholars have been successful and have already made an impact in their organizations upon their return, their level of success has not been explored. Similarly, there have been no empirical studies assessing the level of impact of their REAPs. Besides, there have been cases where AA scholars were less successful or situations in which scholars were unable to implement or complete the implementation of their REAPs due to various reasons. However, several international studies do provide insights into how scholars learn when undertaking employment-oriented scholarship programs.

\section{Existing Literature on Scholarship Learning}

Literature reviews have been conducted on the definition of success in the context of scholarship alumni as they return to their home organization. According to Gladwell (2008), success is a complex interplay between what an individual may bring to the organization and the environmental conditions that may make that person achieve exceptional accomplishments. Under the right circumstances, an individual has the ability to turn challenges as opportunities to attain higher performance making the person successful.

Several factors have been identified to affect or influence the scholar's success. The literature and related studies in this section show certain foci or domains that encapsulate such factors: interpersonal strengths of 
the scholar, higher order skills training, gender parity, experience, among others. These multidimensional factors or characteristics that influence scholars' success are mentioned in the studies or cases below. Clearly, some of these mentioned do not seem to be directly aligned with the same goals as the AAS, yet it is fair to note that there could be a range of employees who can be classified as "scholars" and they undertake different kinds of up-skilling through scholarship programs. The career stages and even occupations of these scholars may be an influence on hindering or facilitating learning and in such case are worth-mentioning here.

Based on the MasterCard Foundation Scholars Program's Theory of Change by Shaw, Sloan, Sridharan and Thomas (2015), there are identified factors that contribute to a scholar's success. These are scholar's personal development of change, positions or jobs that assume leadership roles, mentoring support, built network among other institutions, and pursuit of service-oriented activities.

A study by Ross (2014) identified personal qualities, level of commitment and the kind of assistance the organization afforded to the scholars to have a positive contribution to the success of the Umthombo Youth Development Foundation Scholarship alumni in Africa. In the area of improving patient care, Baillie \& Taylor (2015) highlighted alumni commitment as a facilitative factor for the healthcare scholars in London to be successful in improving services.

In their study on the impact of Jahnigen/GEMSSTAR Scholarship on careers of recipients in geriatric emergency medicine, Rosen et. al (2018) found out that grantees from the said scholarship have been academically productive and successful after the award and that the said award they gained from the program has been instrumental in their career development. 
A survey of the American College of Surgeons (ACS) scholarship recipients, done by Upchurch et al. (2015), resulted to the conclusion that ACS scholarship has a significant impact on the academic career of the grantees despite their increasing clinical burdens. With the said program, there were identified surgeons who became leaders in academic surgery.

Existing literature further suggest that a successful scholar is defined as someone who turns challenges to opportunities (Gladwell, 2008), makes improvements (Rose, Tod, McCabe, \& Giordano, 2017), is committed (Franken et al., 2016), and collaborates and forms interpersonal connections with other individuals and organizations (Cuseo, 2002). Franken, Langi and Branson (2016) emphasized that scholars were successful because they are committed individuals who possess the skills and knowledge to drive change and development. For example, Rose, Tod, McCabe and Giordano (2017) found out that making improvements in their service in-patient care resulted in clienteles' satisfaction. With these improvements, the nurses, midwives and other healthcare professionals promoted excellence in the medical field.

Harsh and Mallory (2013) identified two success factors in the Ron Brown Scholar Program in the United States: one refers to personal factors while the other is on program factors. Personal success factors of the scholar include resilience, efficacy, and academic and leadership potential; while program success factors consist of contribution to society, leadership, connection, and collegial and institutional support.

Martinez, Floyd and Erichsen (2011) mentioned that successful Psychology scholars were productive in publishing research outputs that contribute to the body of literature. Similarly, Li, Miao and Yang (2015) found out that Chang Jiang faculty scholars alumni in China are successful in publishing researches with a high impact factor. This implies that Chinese universities could be geared towards the achievement of 
their goals for scholarly learning through research excellence. In fact, in determining the success of scholars in the academe, the Chang Jiang faculty scholars alumni named alumni linkage and research quality as success indicators. On a similar note, Goldman, Hamburger, \& Ottolini (2014) pointed out that scholarly productivity is an indicator of the success of faculty scholarship alumni teaching at the Department of Paediatrics of the George Washington University School of Medicine and Health. This is manifested in the significant increase in peerreviewed conference presentations and abstract paper publications in various medical research journals. Being productive in publishing research outputs was also suggested by Baillie and Taylor (2015) and Martinez et al. (2011).

An evaluation was done by the Office of Development Effectiveness in 2015 under the Australian Government DFAT regarding the contribution of Australia Awards scholarships to building women's leadership. In this study, it was disclosed that AA scholarships contribute strongly to women recipients in terms of professional development and leadership. Data revealed that AA Awards had historically performed strongly on gender parity from 2012 to 2014 , where $54 \%$ of the awardees were women and $46 \%$ were men.

On the other hand, there are barriers to a scholar's success that should be noted. Franken et al. (2016) indicated that conflict in the workplace, lack of organizational support, and feeling of overburden of Tongan postgraduate scholar hamper success. These are considered cultural norms in Tonga that can impede knowledge sharing and utilization. Baillie and Taylor (2015) have also emphasized that the culture of an organization and colleagues' receptiveness to improvement have a negative contribution to being successful. Dean (1998) highlighted that the lack of motivation to get things done is one barrier to success. Hunt, Morgan, and Teddy (2001) underscored that a heavy workload has a negative contribution to become successful among Maori students. 
The literature cited support the double intent of the reasearch project: to acquire information on the success of scholars, and to explore the factors that facilitate and hinder success with a view to improving recruitment and selection. The overall aim was to use the findings of the survey - described in the next section - to develop a Success Framework which could be useful in selection and support for future AASs.

\section{Methodology}

This study approached the identification of factors central to returning scholars' Success Framework by using a sequential exploratory mixed method. A survey instrument on the factors associated with Australia Awards (AA) success was crafted. The items crafted for the dependent variable ( $\mathrm{Y}=$ success) elicited a response on the level of success of AA scholars, while eight (8) initially identified factors ( $\mathrm{X}=$ facilitating and hindering) served as the independent variables namely: support from the superior, institution, co-workers/colleagues, rank or designation, PAHRODF support, scholar qualities, scholar's motivation, and workload.

The survey questionnaire underwent reliability test using Cronbach's alpha in order to ensure scale reliability and internal consistency of the items with an acceptable coefficient of reliability of 0.86 . Afterwhich, the instrument was sent to all Australia Awards recipients from years 20052014 all over the Philippines. These scholars were asked to respond to the online survey posted on the PAHRODF website. They were made to answer the questionnaire's every item using scale of 1-10 of which 1 is the lowest and 10 the highest. Out of 1,222 target AA scholars, only 200 scholars (16\%) - all categorized successful - had filled out completely the online survey instrument while others who did not do so were not included in the analysis. The data gathered from this survey became the basis for coming up with the success framework. 
After the responses were retrieved, the data were treated statistically. Mean and percentage distributions were used to show the profile of the respondents in terms of age, sex, level of postgraduate scholarship, scholarship category, nature of the organization, position in the organization, the level of success of AA scholars (categorized into very highly successful, highly successful and successful), and the factors associated with their success.

A regression model was then generated from the survey data for initial analysis. It was checked for multi-collinearity to correct the model for some statistical errors. Outliers were removed by eliminating or removing extreme values in the data. To further correct the model for misbehaving variables, Principal Component Analysis (PCA) was used to examine the interrelations among the set of variables in order to identify the underlying structure of those variables as well as to further check for multi-collinearity issues thus combining variables (factors) that are highly correlated. Hence, from the eight factors, they were then reduced to six factors wherein the variable "institution" and "co-workers/ colleagues" were renamed as Organization (I), while rank or designation and workload were renamed Assignment (AS). Then a second model was generated utilizing the six factors which became the final model of this research.

It should be noted, however, that because of the limited literature gathered, and aside from the fact that most of them are international in nature, the researchers deemed it important to take into account the Filipino scholars' construct of "success" as well as its contributory factors, for concepts might be lacking if additional insights from the scholars were not asked. Aside from that, their actual experiences were deemed to be of great help in coming up with a more contextualized definition of success and the factors and indicators affecting their success. This is the purpose of the focus group discussion conducted with scholars 
representing various sectors in the Philippines. Although not part of the core data, FGD results aided in conceptualizing the frame and finalizing the survey questionnaire.

\section{Results}

\section{Scholars' Demographics Profile}

From the 200 AA scholars who responded, 15 percent aged 26-35, 45 percent $36-45$, and 35 percent $46-55$ years old. The remaining 5 percent were 56 years old and above. In terms of gender, 59 percent of the respondents were female. Majority of the respondents had Masters' coursework (63\%), followed by Postgraduate Diploma or Graduate Certificate (21\%), PhD or EdD (11\%), Masters' Research (5\%), and Masters' Honors (1\%).

In terms of the nature of scholar's employment, the majority of returning scholars represented government agencies and private organizations. The government offices included the education sector (47\%), environment (12\%), human resources and organizational development $(9 \%)$, and social work $(8 \%)$. A private organization represented the sector from trade and economics (7\%). About 17 percent of the respondents did not indicate their affiliations. The government sector numbers are not surprising as this sector is prioritized because these grantees are tenured, are receiving salaries while on scholarship, and have institutions to return to. These factors make it more likely that their REAP programs will be implemented and potentially sustainable.

Figure 1 shows that 24 percent of the respondents occupied technical positions in their respective organizations. Twenty-eight percent of the respondents had supervisory positions; 11 percent managerial positions; 25 percent in teaching profession (high school and college); and 11 percent had administrative functions. 


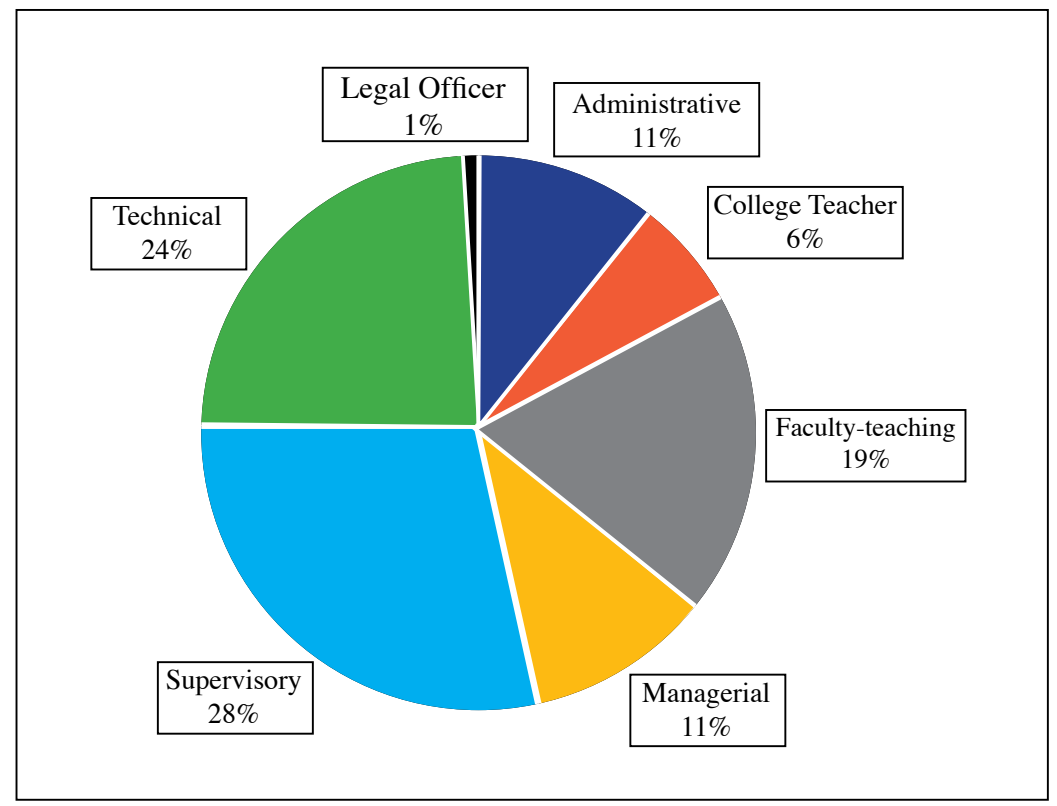

\section{Figure 1}

Scholars' position level in their organizations

Further characteristics of the surveyed scholars showed that they perceived themselves very highly successful (55.17 percent), highly successful (27.59 percent), and successful (17.34 percent). They perceived themselves as having commitment or passion, i.e. committing themselves to initiate change in their organization on a higher level of development, determined to accomplish whatever activities they initiated, and having the passion in getting things done despite challenges encountered. As successful scholars, they made appropriate adjustments which implies they have the capacity to be innovative. The results suggest they were adaptive to organizational change, could find alternative means to address organizational concerns, and were able to offer new perspectives on existing policies that needed improvement. And as an outcome of the said scholarship, they had established strong connections or linkages with other organizations and were able to touch lives through convergence effort with their team. 


\section{Factors affecting Success of AA Scholars}

Shown in Figure 2 is the percentage distribution of AA scholars who rated the extent to which the factors identified affected their level of success. All scholars agreed that their qualities had contributed to a great extent to their success. Still, a majority of them expressed that a scholar's motivation, PAHRODF support, organization, assignment and support from superiors were factors that also facilitated their success to a great extent.

120

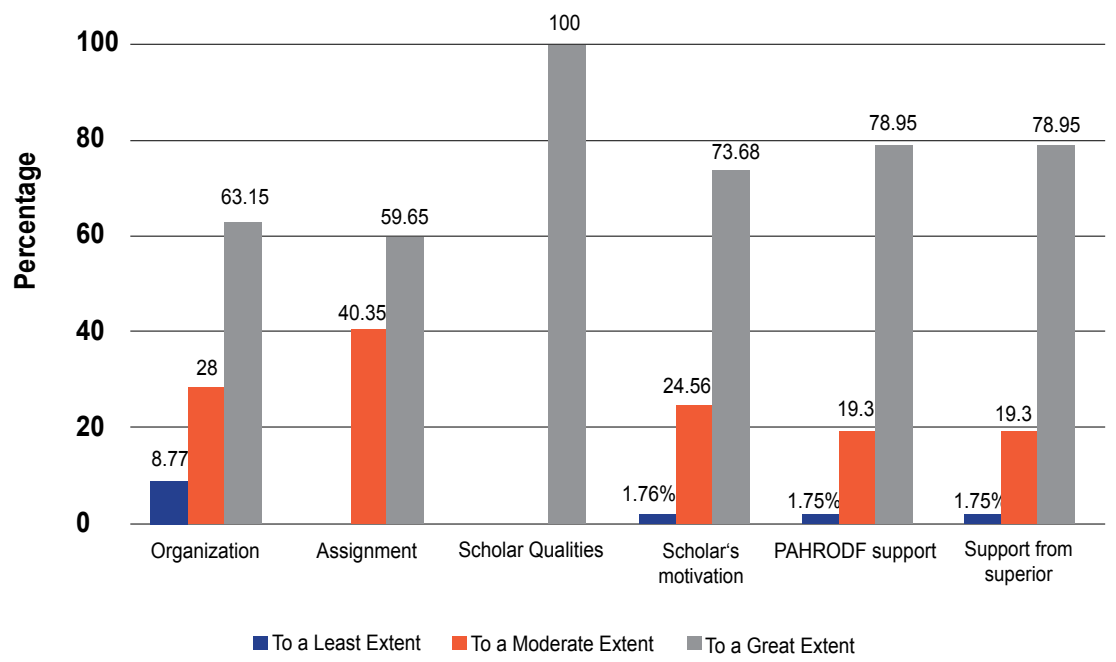

Figure 2

Factors affecting AA Scholars'Success 


\section{Success Framework}

A scholar's success $\mathrm{Y}_{\mathrm{s}}$ may be predicted by looking at some facilitating $\left(\mathrm{F}_{\mathrm{i}}\right)$ and hindering $\left(\mathrm{H}_{\mathrm{i}}\right)$ factors as predictors, such that

$$
\mathrm{Y}_{\mathrm{s}}=\mathrm{f}\left(\mathrm{F}_{\mathrm{i}}, \mathrm{H}_{\mathrm{i}}\right)
$$

(equation 1)

where;

$$
\begin{aligned}
& \mathrm{Y}_{\mathrm{s}} \text { is the index of success } \\
& \mathrm{F}_{\mathrm{s}} \text { are the facilitating factors } \\
& \mathrm{H}_{\mathrm{i}} \text { are the hindering factors }
\end{aligned}
$$

Given these, the framework assumed that,

$$
Y_{S}=\beta+\alpha S+\mu I+\partial C+\eta R D+\sigma P S+\dot{\omega} S Q+\rho S M+\tau W+\varepsilon
$$

(equation 2)

where facilitating and hindering factors are expected to have positive and negative signs, respectively.

By multiple regression, the following final equation was generated:

$$
Y_{s}=\beta-a I+\eta A S+\mu S Q+\sigma S M+\tau P S-\alpha S+\varepsilon
$$

(equation 3)

where I stands for organization; AS for assignment, SQ for scholar qualities, SM for scholar's motivation, PS for PAHRODF Support, and $S$ for support from superior. (See Table 1 for the results) 
Table 1. Regression results

\begin{tabular}{|l|c|c|}
\hline \multicolumn{1}{|c|}{ Factors } & Beta coefficient & p-value \\
\hline Organization (I) & -.042 & .567 \\
\hline Assignment (AS) & .195 & $.039 *$ \\
\hline Scholar Qualities (SQ) & .282 & .082 \\
\hline Scholar's motivation (SM) & .055 & .507 \\
\hline PAHRODF support (PS) & .031 & .683 \\
\hline Support from superior (S) & -.056 & .535 \\
\hline
\end{tabular}

*significant @0.05

Based on the given data, the success of AA scholar can be represented by the following equation:

$$
\begin{aligned}
& Y i=4.849-0.042 I+0.195 A S+0.282 S Q+0.055 S M+0.031 P S-0.056 S \\
& \mathrm{R}^{2}=0.22 \quad \text { (equation 4) }
\end{aligned}
$$

From the results, based on the signs of the beta coefficient, it turned out that assignment, scholar qualities, scholar motivation, and PAHRODF support are the facilitating factors, while Organization and Support from superior are the hindering factors of success although not statistically significant. Further, it is suggestive of the idea that AA scholars' assignment (see Figure 3) is the only factor that can facilitate success. This finding corroborates with the results of Shaw et al. (2015) that position or job in the organization affects the level of success of returning scholars. It still has to be noted that to some degree, scholars' qualities can also facilitate success, as supported by Ross (2014), who elaborated that personal qualities can contribute to the scholar's success. 


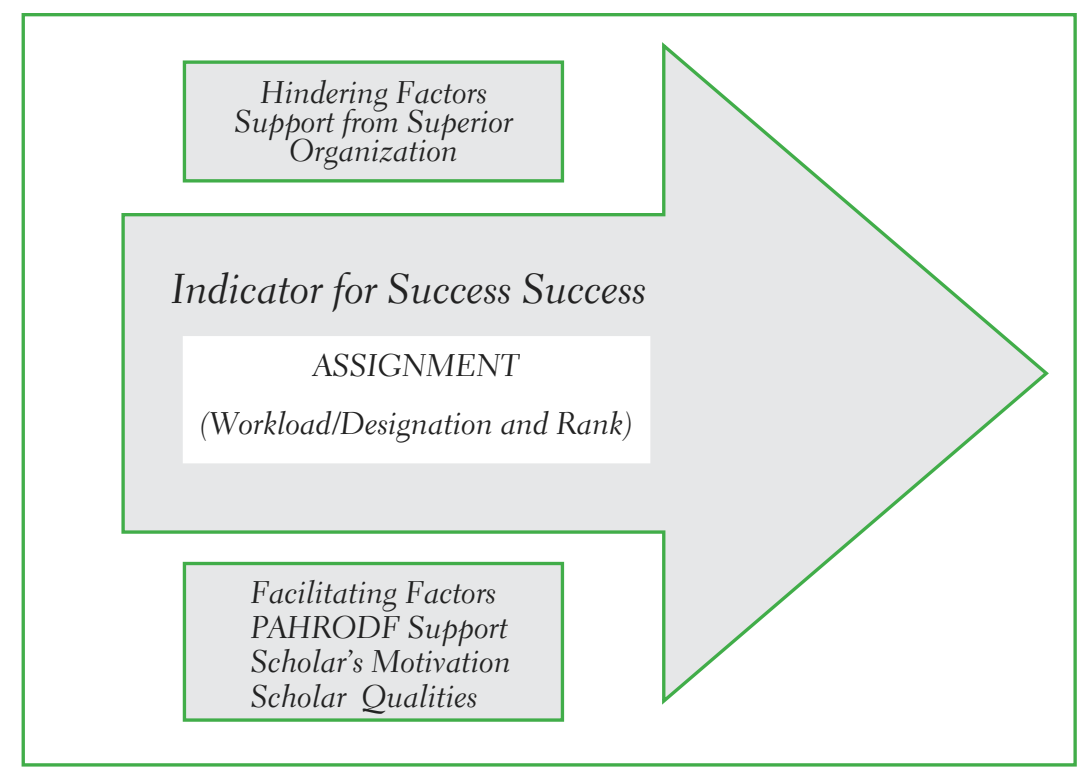

Figure 3

Success Framework

The framework appears to be significant in which variation of the success of the AA scholars is accounted for by the different factors affecting success. In this result, the obtained $\mathrm{R}^{2}$ was 0.22 , which means only 22 percent of this variation is being explained by the model, bearing in mind that the $\mathrm{R}^{2}$, the coefficient of determination, measures the percentage of variation in the dependent variable that is being explained by the variation in the independent variable. The remaining 88 percent of the outcome parameters assumed is unexplained by the model. According to Moksony (1990), Reisinger (1997) and Singleton (2002), low $\mathrm{R}^{2}$ for social science research is acceptable and especially when dealing with cross-sectional data. This suggests that the variance in the population being studied can strongly influence $\mathrm{R}^{2}$ magnitude. Thus, $\mathrm{R}^{2}$ is not the same as goodness-of-fit and is a poor measure of it (Fonticella, 2019; Barclay, 1991). 
Notwithstanding the fact that high values of $\mathrm{R}^{2}$ are ideally better, in this study, the low $\mathrm{R}^{2}$ can still be useful to provide a framework for success, but maybe in low precision. In this investigation, there is an association between success and its associated factors, and using the equation, we can indeed predict one from the other. However, the accuracy of this prediction needs to be considered and thought of prudently when using it as a framework. As such, further validation of the model using new datasets may be done or may use confirmatory analysis of the findings using much larger sample before the regression equation would be recommended for use. Thus, reporting the findings of this study is still necessary and relevant since great results typically start as ideas in small datasets.

\section{Discussion}

The Success Framework is designed to support the attainment goal of AA Scholars' capacity building as a subset of the United Nation's sustainable development goals and investing in the next generation of global leaders for sustainable development. Part of the sustainability effort is to ensure that these scholars receive the appropriate support so that learning gained is not wasted and eventually utilized in countries most in need of them.

Institutional support is extremely important to returning scholars' eventual success as they apply their new learning to their home institutions. From the framework, assignment (workload, designation, and rank) is a contributory factor in determining the success of returning scholars. The nature of work of the scholars allows them to implement their planned projects. As several of the respondents confirmed that they had been supported by their institutions, it should be underscored that a scholar's individual intentions and goals to effect change may only be 
actualized when the needed support is provided. As the scholar brings in his or her advanced knowledge and skills into the workplace, the institution he or she is part of should step up and accommodate ideas and innovations brought on by the scholar - this if they want their human resource investment returned. Conversely, the lack of institutional and management support could be a hindering factor. Hence, success happens when a scholar is supported by the organization in terms of time, financial, and other resources.

\section{Conclusion}

Based on the findings of the study, it can be said that AA scholars shall be successful if the organizations they work for have a clearly defined human resource development plan specifically related to recognizing employee outputs or contributions to the organization, in terms of promoting employees and providing opportunities for growth. Additionally, scholars shall be successful if organizations have a clear plan to implement or provide support for the implementation of the REAP, and if there is a management team (supervisors, especially) that ensures a workplace is "ready" for the scholar's inputs.

Additional factors involve continuing support from PAHRODF, such as the provision of seed funds or grants to a scholar's REAP and other projects, incentives for recipients of AA Alumni Innovation Excellence Awards, and provision of a venue for scholars to present their completed REAP and other accomplishments. This could aid in the attainment of the objective of PAHRODF, that is, to develop and enhance competencies related to human resource management and development, policy and planning, management and leadership, and financial administration, as well as organizational capacities and systems to support service delivery. These are critical help to the scholars 
in implementing what they have planned for as contribution to the development of each of their organizations.

The results of this study suggest further a more transparent and standardized approach in vetting qualified candidates. It qualifies that when selecting future AA scholars, PAHRODF has to prioritize those whose record in terms of leadership skills is exemplary. Whether these leadership skills could be demonstrated through their academic records, organizational work, or volunteerism in their respective communities, the scholar's qualities should also shine throughout his/her professional track record or profile, when being considered or vetted to be granted the scholarship award. Hence, those who hold positions and have access to decision-making in their respective institutions could be prioritized in being granted the scholarship. Those with a solid leadership track record in their assignments are proposed to be prospective successful AA scholars. They are more likely to take the initiative (and risks), and more likely to utilize their leadership abilities in helping their institutions bring about change. As well, potential scholars who likely possess the desirable qualities of being committed and passionate, and having the ability to establish networks with other organizations, are considered to guarantee overall success of the scholars. 


\section{References}

Australia Awards Philippines. (n.d.). Re-entry action plan. Retrieved from https://www.australiaawardsphilippines.org/about-1/re-entryaction-plan

Baillie, L., \& Taylor, R. (2015). The ripple effect: personal scholarships and impact on practice development. International Practice Development Journal, 5(1). Retrieved from http://search.proquest. com/openview/e378cd5036f4df1de475c4a86c817030/1?pqorigsite $=$ gscholar\&cbl $=2030535$

Barclay, D Lee. (1991). A Statistical Note on Trend Factors. The Meaning of "R-Squared". Retrieved on July 2019. https://www.casact.org/ pubs/forum/91fforum/91ff007.pdf

Coffey International Limited. (2015). A study of international academic collaboration and partnerships (p. 68). Philippines Australia Human Resource and Organisational Development Facility.

Cuseo, J. (2002). Student success: Definition, outcome, principles and practices. In Esource for College Transitions. University of South Carolina: National Resource Center for the First-Year Experience \& Students in Transition. Retrieved on July 23, 2019. https:// www2.indstate.edu/studentsuccess/pdf/Defining\%20Student $\% 20$ Success.pdf.

Dean, A. (1998). Defining and achieving university student success: Faculty and student perceptions. Virginia Polytechnic Institute and State University, 95.

Fonticella, R. (2019). The Usefulness of the $\mathrm{R}^{2}$ Statistic by Ross Fonticella, ACAS. Retrieved on June 23, 2019. https://www.casact.org/pubs/ forum/98wforum/98wf055.pdf 
Franken, M., Langi, N. T. K., \& Branson, C. (2016). The reintegration of Tongan postgraduate scholars after study abroad: knowledge utilization and resituation. Asia Pacific Education Review, 17(4), 691-702. https://doi.org/10.1007/s12564-016-9462-5

Gladwell, M. (2008). Outliers: The story of success. New York: Little, Brown and Company.

Goldman, E., Hamburger, E., \& Ottolini, M. (2014). Building Educational Scholarship: A Roadmap for Success. The Journal of Faculty Development, 28(3), 47-54.

Harsh, S., \& Mallory, M. (2013). The future of education: Building capacity for success. Delta Kappa Gamma Bulletin, 80(1), 16-25.

Hunt, H., Morgan, N., \& Teddy, L. (2001). Barriers to and supports for success for Maori students in the Psychology Department at the University of Waikato. Hamilton, New Zealand: Department of Psychology, University of Waikato. Retrieved on July 23, 2019. https://researchcommons.waikato.ac.nz/bitstream/ handle $/ 10289 / 466 /$ content.pdf?sequence $=1$ \&is Allowed=y

Li, F., Miao, Y., \& Yang, C. (2015). How do alumni faculty behave in research collaboration? An analysis of Chang Jiang Scholars in China. Research Policy, 44(2), 438-450. https://doi.org/10.1016/j. respol.2014.09.002

Martinez, R., Floyd, R., \& Erichsen, L. (2011). Strategies and attributes of highly productive scholars and contributors to the school psychology literature: Recommendations for increasing scholarly productivity. Journal of School Psychology. 49(6):691-720. doi: 10.1016/j.jsp.2011.10.003. Epub 2011 Dec 14. 
Reisinger, H (1997), The impact of research designs on $\mathrm{R}^{2}$ in linear regression models: an exploratory meta-analysis. Journal of Empirical Generalisations in Marketing Science, Vol. 2, No. 1. Retrieved on July 23, 2019. https://www.empgens.com/wp- content/uploads/1997/06/ ResearchDesignsR ${ }^{2}$.pdf

Rose, M., Tod, A., McCabe, C., \& Giordano, R. (2017). An evaluation of the Florence Nightingale Foundation scholarships. Nursing Standard, 31(21), 40-44.

Rosen, T., et al. (2018). Impact of Jahnigen/GEMSSTAR Scholarship on Careers of Recipients in Emergency Medicine and on Geriatric Emergency Medicine. Acad Emerg Med. doi: 10.1111/acem.13396. Retrieved on July 2019.

Ross, A. (2014). Building on Tinto's model of engagement and persistence: Experiences from the Umthombo Youth Development Foundation Scholarship Scheme. African Journal of Health Professions Education, 6(2), 119. https://doi.org/10.7196/ajhpe.404

Shaw, A., Sloan, M., Sridharan, S., \& Thomas, C. (2015). Learning across borders: The collaborative creation of monitoring, evaluation, and learning framework for the MasterCard Foundation Scholarship Program. Retrieved from http://www.disabilitypolicyresearch. org/ / media/publications/pdfs/international/ukfiet_2013_mcf_ mpr.pdf

Singleton, G. R. (2002). Geologic Storage of Carbon Dioxide: Risk Analyses and Implications for Public Acceptance. Retrieved on July 23, 2019 https://sequestration.mit.edu/pdf.GregSingleton_Thesis.pdf

Upchurch G, Freischlag J, Novicoff W, et al. Survey of the American College of Surgeons scholarship recipients: a story of generating academic leaders. J Am Coll Surg. 2015;220:1122-1127. 